\title{
Performance analysis of E-shaped dual band antenna for wireless hand-held devices
}

\author{
Balamurugan Rajagopal ${ }^{*^{*}}$ and Lalithambika Rajasekaran ${ }^{2^{*}}$
}

\author{
* Correspondence: \\ megalaimurugan@yahoo.com; \\ srlalithambika@gmail.com \\ ${ }^{1}$ Assistant Director (Administration), \\ All India Council for Technical \\ Education, New Delhi, India \\ ${ }^{2}$ Post Graduate Engineer, Anna \\ University (Regional Centre \\ Coimbatore), Tamil Nadu, India
}

\begin{abstract}
Due to evolution in wireless applications, the high performance dual band handsets were blooming in the market. In this paper, a compact dual band E shaped planar inverted $\mathrm{F}$ antenna is presented, which is suitable for GSM application in handheld devices. Here, antenna is described for GSM (900 MHz and $1800 \mathrm{MHz}$ ), which covers (831 MHz - $973 \mathrm{MHz}$ and $1700 \mathrm{MHz}-1918 \mathrm{MHz}$ ) $10 \mathrm{~dB}$ bandwidth. The designs and simulations are performed using Finite Difference Time Domain (FDTD) technique based General Electro Magnetic Simulator - Version 7.9 (GEMS-7.9). The performance analysis of E-shaped antenna also includes real world interaction between antenna element and Spherical human head model composed of three layers, skin, skull and brain. The simulated results including, S-Parameter, radiation pattern, current distributions and Specific absorption rate, thermal distributions have validated the proposed E shaped antenna design as useful for compact mobile phone devices with comparatively low average Specific Absorption Rate in market.
\end{abstract}

Keywords: Dual band antenna; GSM (Global System for Mobile communication); PIFA (Planar Inverted F-antenna); S - Parameter; Specific Absorption Rate (SAR); Finite Difference Time Domain (FDTD); General Electro Magnetic Simulator (GEMS)

\section{Introduction}

Over last decade, the evolution of wireless communication devices has increased rapidly to fulfill the requirement of high performance mobile portable devices which includes smart phones, Tablets, Notebooks etc. The handset antenna which, plays a transceiver role in mobile phone handset, should be optimized for better performance. In addition to the electrical requirements, the design of a handset antenna has to take into account the resulting exposure of the user. However, there has also been increase in concern regarding ill effects of Radio Frequency (RF) emitted by mobile phone antennas. These adverse health effects can be assessed by measuring power coupled to human tissue and thermal change, by using dosimetry called Specific Absorption Rate. The international commission on non-ionizing radiation protection and IEEE provides radiation level limit for the consumer products in free space.

Now a days variety of multiband internal antennas are reported, which are highly preferred for slim mobile phone due to their compactness [2,7]. The following literature survey shows the implication of dual band antenna in mobile phone communications. Dual band antenna (MIMO) can be used for LTE band $(0.746-0.787 \mathrm{GHz})$ and the M-WiMAX $(2.5-2.69 \mathrm{GHz})$. It consists of two identical elements, each of which 
is $15 \times 13.25 \mathrm{~mm}^{2}$. The minimum separation between two elements is $0.5 \mathrm{~mm}$ [14]. Novel coplanar waveguide fed planar monopole antenna with dual-band operation for Wi-Fi and 4G LTE. It's operating bands consists of $2.3-3.0 \mathrm{GHZ}, 4.7$ to $5.9 \mathrm{GHz}$ are achieved by carefully optimizing the position and size of a smiling slot. Antenna is characterized in terms of return loss, radiation pattern, and measurement in anaerobic champers [16].

A connected E-shaped and U-shaped dual band patch antenna for operating frequencies $2.46 \mathrm{GHz}$ and $4.9 \mathrm{GHz}$ is designed and the bandwidth variation is analyzed by changing the height of substrate, bridge width etc. for different wireless LAN applications. The simulation studies are performed using GEMS simulation software [21]. A compact planar inverted E-shaped dual band antenna is designed over PCB board of $10 \times 5 \times 4 \mathrm{~mm}^{3}$ and good performance characteristics observed at $2.4 \mathrm{GHz}$ and $5.5 \mathrm{GHz}$ makes this antenna suitable for mobile device applications [22].

In many commercial wireless applications, PIFA and PMA are extensively used because it is simple, compact with good radiation pattern with sufficient Bandwidth. Normally, the electrical characteristics of handset antenna mainly depend on the ground plane on which the antenna is fabricated and also on the phone casing. The bandwidth of the antenna element increases, if the casing also resonates at operating frequency. Bandwidth and radiation characteristics make the $2 \mathrm{G}$ dual band antenna suitable to be used for Wi-Fi and 4G LTE applications in the $2.4 \mathrm{GHz}$ to $2.7 \mathrm{GHz}$ band and also $5.1 \mathrm{GHz}$ to $5.875 \mathrm{GHz}$ band [13]. Currently, GSM (Global System for Mobile Communication) is a standard protocol for digital mobile communication used for phone calls and transmission of text messages, which is addressed in this paper [3].

In this paper, E shaped PIFA with dual band 900/1800 $\mathrm{MHz}$ has been introduced [2]. The design considerations and simulated results for the Proposed E shaped antenna such as, return loss, radiation pattern and current distributions were also analyzed. Further, the performance analysis of E shaped antenna is described by considering the real world environment in which, mobile phone is expected to operate. The near field environment are created with mobile phone model which includes antenna element, battery, exterior plastic shell and three layered human head model. Simulation and performance analysis of proposed E shaped antenna are performed using FDTD based GEMS simulator [11].

Section Numerical modelling includes the modeling technique and the modeling of antenna and near field interactive devices. Section Performance analysis of antenna in free space involves parametric analysis of E shaped antenna and current distributions in free space. Section Influence of near field on antenna performance discusses the influence of near field environment when antenna is in close proximity to a human head model. Finally, section Conclusion provides conclusion.

\section{Numerical modelling}

Maxwell's equations can be solved in the time whereas for frequency domain many EM simulation techniques available using FDTD $[17,18]$. If the problem size grows, FDTD approach provides excellent scaling and the Broadband output can be obtaining using time domain approach. FDTD leads other computational methods say Finite Element method, Method of Moments etc. when the number of size of computational space increases. For studying, biological effects of Electromagnetic radiation from Wireless 
devices FDTD is better, which is the technique employed in our work. Further, FDTD also provides accurate results of the filed penetration into biological tissues.

\section{Numerical formulation using FD-TD technique}

In this work, finite difference time domain technique is used throughout the work, which can be formulated using Maxwell's curl equations,

$$
\begin{aligned}
& \nabla \times \mathrm{E}(\mathrm{r}, \mathrm{t})=-\partial \mathrm{B}(\mathrm{r}, \mathrm{t}) / \partial \mathrm{t} \\
& \nabla \times \mathrm{H}(\mathrm{r}, \mathrm{t})=\mathrm{J}(\mathrm{r}, \mathrm{t})+\partial \mathrm{D}(\mathrm{r}, \mathrm{t}) / \partial \mathrm{t}
\end{aligned}
$$

Where, the equation involves electric field strength (E) and electric flux density (D), magnetic field strength $(\mathrm{H})$ and magnetic flux density (B), electric current density (J) and electric charge density ( $\rho$ e). Current density produces magnetic field around it. From the curl equation, we observed that the time derivative of the E-field depends on the change of the $\mathrm{H}$-field across space. Hence, the value of the E-field can be computed if we know its previous value and the space-derivative of the $\mathrm{H}$-field, which in turn is time-stepped and if initial field value, initial conditions and boundary conditions are known [4]. The FDTD technique divides the computational space into a Cartesian coordinate's grid of voxels and then allocates the components of the electric and magnetic fields as every E field is surrounded by $\mathrm{H}$ field and vice versa. This scheme is known as Yee lattice. If, the current changes over time, alternating magnetic field causes alternating electric field, which in turn causes another magnetic field, results in the creation of propagating electromagnetic wave of higher frequency.

There are certain commercially available EM simulators (say SEMCADx, GEMS etc.) which employ FDTD technique for computation. The computational performance of SEMCADx is as follows (Min grid size $(\mathrm{mm})$ is 300 , Computational domain is $14.2 \mathrm{M}$ cells; Simulation time is $<15 \mathrm{~min}$, Simulation Speed is $300 \mathrm{M}$ cells/s $[19,20]$.

A FDTD based electromagnetic simulator (GEMS version -7.9) is used throughout the work. The FDTD modeling including head and hand model consists of 739675 cells. The convergence of the simulated solutions has been checked for every 100 time steps and the solutions are set to be converged for S- parameter calculations.

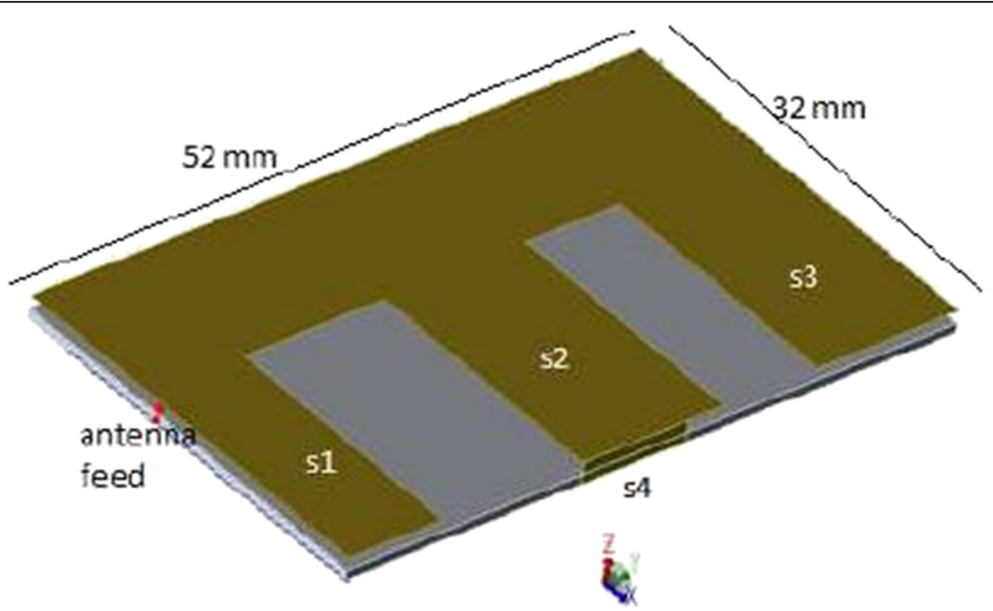

Figure 1 Structure of proposed compact dual band E shaped antenna. 

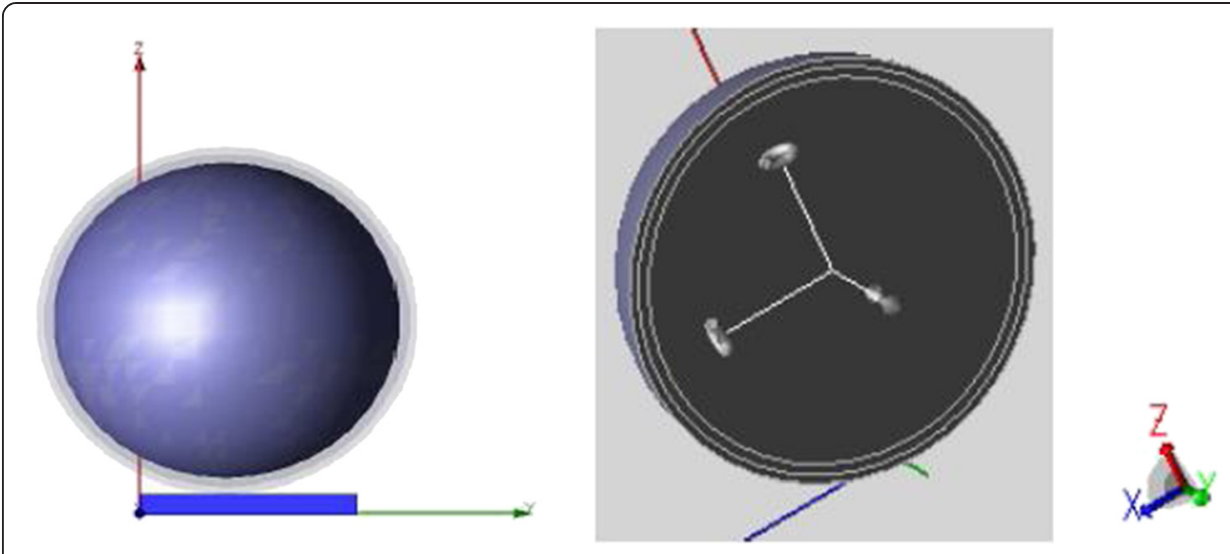

Figure 2 Mobile handset interactions with layered spherical head model.

\section{E - shaped antenna design}

The configuration of proposed E shaped antenna is shown in Figure 1. In general, traditional PIFA [1,4] is composed of metal strip, feeding line and shorting structure. The Antenna element has rectangular ground plane $(52 \mathrm{~mm} \times 32 \mathrm{~mm}$ ). The radiating element composed of feed line $(52 \mathrm{~mm} \times 12 \mathrm{~mm})$, patch $S_{1}(20 \mathrm{~mm} \times 8 \mathrm{~mm})$, patch $\mathrm{S}_{2}$ $(12 \mathrm{~mm} \times 20 \mathrm{~mm})$, patch $\mathrm{S}_{3}(12 \mathrm{~mm} \times 20 \mathrm{~mm})$. There is free space (height $\left.=1.8 \mathrm{~mm}\right)$ between the antenna top plate and the substrate.

The substrate material used is of thickness $\mathrm{t}=2 \mathrm{~mm}$. The dimension of the shorting plate (S4) is $10 \mathrm{~mm} \times 1.8 \mathrm{~mm}$. The distance between the feeding and the shorting plate is $27 \mathrm{~mm}$ [6]. The radiating $\mathrm{E}$ element is modeled as perfect electric conductor. The excitation port is modeled as lumped port with internal resistance being $50 \Omega$. Maximum working frequency of $3 \mathrm{GHz}$ is allowed for performance analysis of radiating antenna.

\section{Handheld device model and user head model}

In order to meet the expected handset performance in this work, we not only contend with designing antennas but also in need mitigating the RF interaction with the near field environment, which influences the E-shaped antenna performance. Figure 2 shows the hand held device model which is in close proximity to spherical human head model.

The device composed of E shaped antenna, battery $(20 \mathrm{~mm} \times 25 \mathrm{~m} \times 2.5 \mathrm{~mm})$ and plastic cover $(80 \mathrm{~mm} \times 45 \mathrm{~mm} \times 5 \mathrm{~mm})$ which, encloses all the components. The dielectric constant used for the plastic cover is 4.4. The antenna and battery were modeled as metal materials [10]. The spherical head model consisting of three layers

Table 1 Properties of human tissues

\begin{tabular}{|c|c|c|c|c|c|c|}
\hline \multirow{2}{*}{$\frac{\text { Tissue }}{\text { Human adult }}$} & \multicolumn{2}{|c|}{ Brain diameter $(\mathrm{mm})$} & \multicolumn{2}{|c|}{ Skull thickness (mm) } & \multicolumn{2}{|c|}{ Skin thickness $(\mathrm{mm})$} \\
\hline & 160.1 & & 8.9 & & 7.2 & \\
\hline Tissue density ( $\mathrm{Kg} / \mathrm{m} 3)$ & 1030 & & 1085 & & 1010 & \\
\hline Operating frequency & $0.9 \mathrm{GHz}$ & $1.8 \mathrm{GHz}$ & $0.9 \mathrm{GHz}$ & $1.8 \mathrm{GHz}$ & $0.9 \mathrm{GHz}$ & $1.8 \mathrm{GHz}$ \\
\hline Permittivity & 55.0 & 53.0 & 8.0 & 8.0 & 34.5 & 32.5 \\
\hline conductivity & 1.23 & 1.7 & 0.11 & 0.16 & 0.6 & 0.52 \\
\hline
\end{tabular}




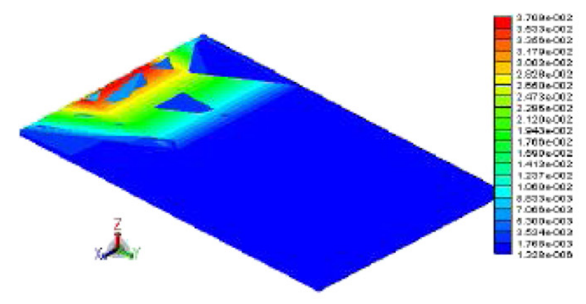

(a)

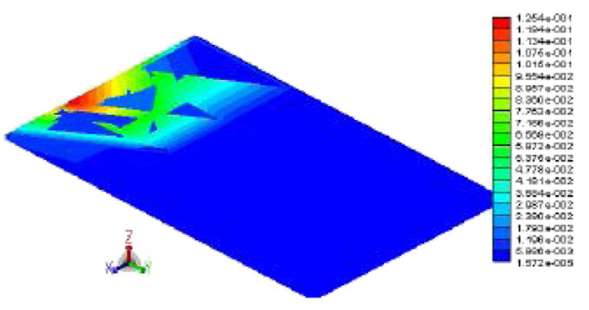

(b)

Figure 3 (a) \& (b): current distribution in ground plane for $0.9 \mathrm{GHz}, 1.8 \mathrm{GHz}$ respectively. Surface current in the ground plane is higher near feeding point.

skin, skull and brain (as shown in Table 1) [8] is selected for the simulation study. The conductivity, permittivity and density of tissues which is a function of frequency (as shown in Table: 1) are an important factor in power coupled to human tissues [12]. The phone model is placed at three different distances from the side of the head and simulated results were compared for analysis.

\section{Performance analysis of antenna in free space}

The design objective is a dual band portable handheld device antenna suitable for 900/ $1800 \mathrm{MHz}$ GSM application. We optimize the design through simulation using General Electro - Magnetic Simulator (GEMS), a commercial software package based on Finite Difference Time Domain(FDTD) technique [10].

\section{Current distributions}

While using the handset, the pulsed current flows from the battery to radiating element. This excitation gives rise to magnetic field around the handset.

Figure 3 shows the current distributions in ground plane at $900 \mathrm{MHz}$ and $1800 \mathrm{MHz}$ respectively. The excitation of feeding port at right end of the E - shaped Antenna shows high magnitude surface current at the proximity of feeding point and becomes almost zero near the open end. This coupled current also affects the antenna performance by inducing heat around the handset device.

Figure 4 shows the current distributions in radiating E-shaped radiating element at $900 \mathrm{MHz}$ and $1800 \mathrm{MHz}$ respectively. The excitation of feeding port induces high magnitude surface current in proximity of feed but weak or null current in the area far from the feed [5]. Further, the weak surface current on the ground plane ensures the

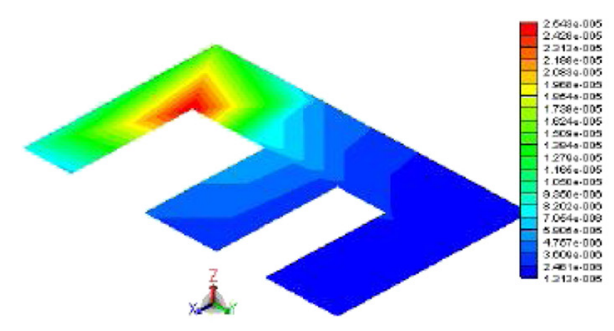

(a)

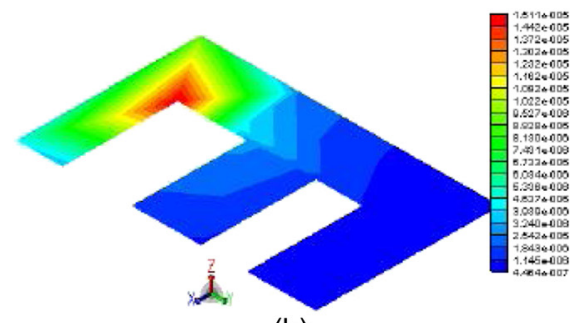

(b)

Figure 4 (a) \& (b): current distribution in E shaped antenna element at $900 \mathrm{MHz}, 1800 \mathrm{MHz}$ respectively. Lower surface currents other than feeding point ultimately reduces power coupled. 


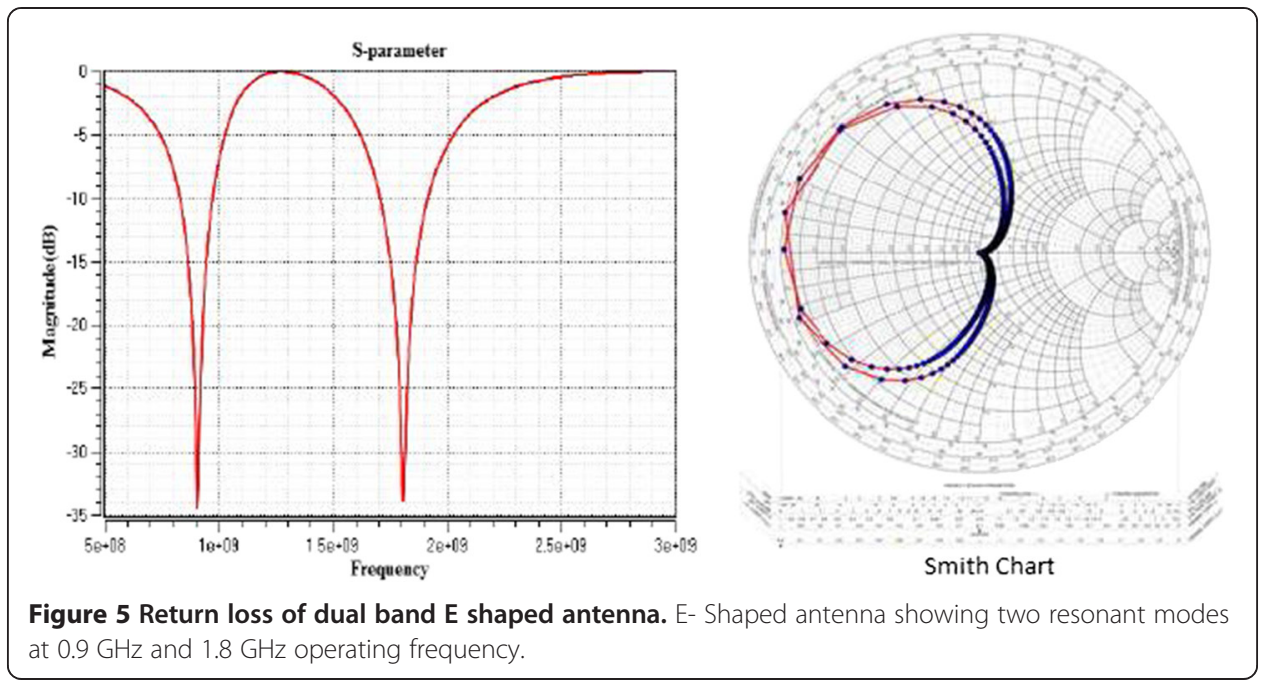

better antenna performance by reducing the specific absorption rate (SAR), where power coupled to human tissues when antenna is in proximity to users head. Since, the mobile handset is usually held close to the human body during the operation, it is necessary to analyze the current distribution as a function of distance (in section Influence of near field on antenna performance).

\section{S- parameter}

The simulated S parameter and smith chart representation for the dual band E shaped antenna is shown in Figure 5. Simulations were carried out using GEMS, a FDTD based simulator [7]. The results indicate the return loss better than $25 \mathrm{~dB}$ which can be seen above. It is observed that the $10 \mathrm{~dB}$ bandwidth covers $831 \mathrm{MHz}-973 \mathrm{MHz}$ and $1700 \mathrm{MHz}-1918 \mathrm{MHz}$. This satisfies the required bandwidth for GSM 850/900/ $1800 \mathrm{MHz}$ when compared to other proposed antennas as in [2,7].

Bandwidth is one of the very important characteristics which make the $2 \mathrm{G}$ dual band antenna suitable to be used for 4G LTE applications. For example, the $10 \mathrm{~dB}$ bandwidth of proposed antenna covers LTE band-19 of NTT Docomo (Japan) which has uplink of (830-845) $\mathrm{MHz}$ and downlink of (875-890) MHz and LTE band-3 of NTT Docomo (Japan) has uplink of (1764-1784) MHz and downlink of (1859-1879) MHz. Similarly, FAReastone (Taiwan) covers LTE band-3 with uplink (1735-1755) MHz and downlink

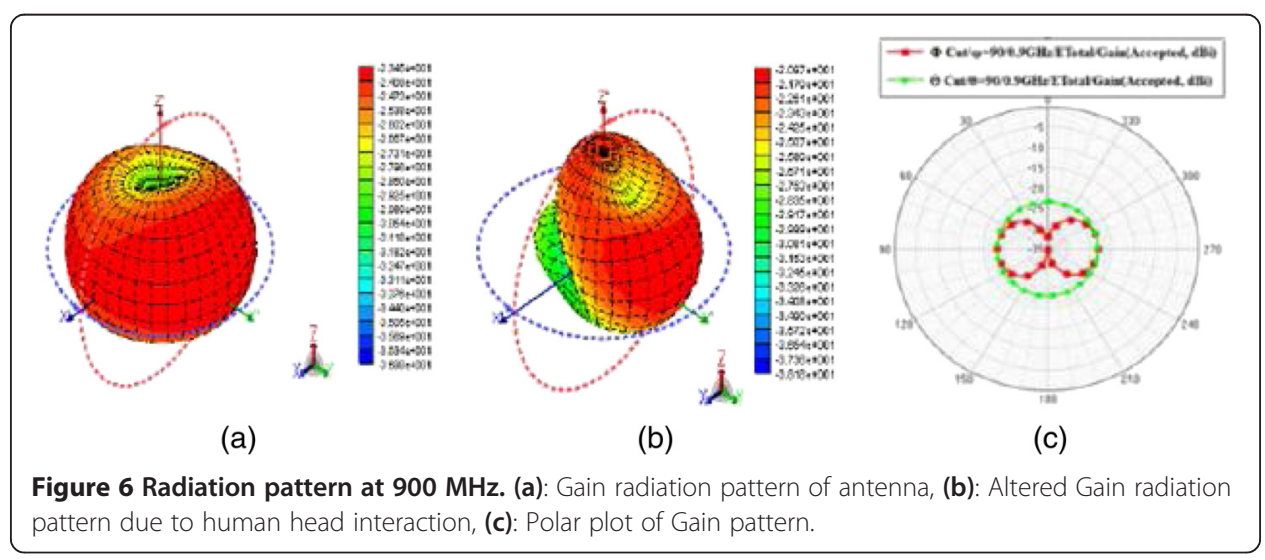




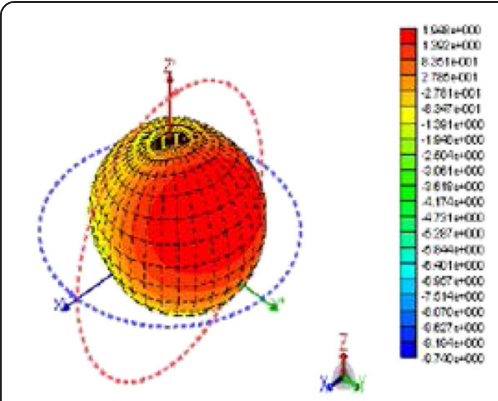

(a)

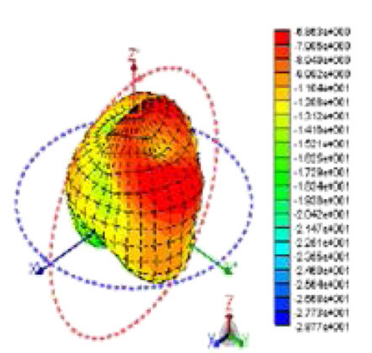

(b)

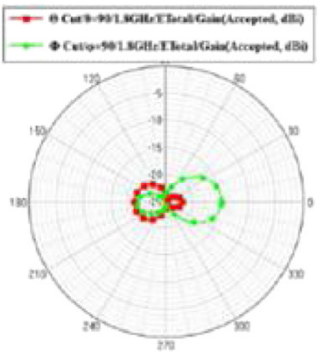

(c)

Figure 7 Radiation pattern at 1800 MHz. (a): Gain radiation pattern of antenna, (b): Altered Gain radiation pattern due to human head interaction, (c): Polar plot of Gain pattern.

of (1830-1850) MHz. Hence, the proposed antenna can also be employed for 4G LTE applications [15].

\section{D- radiation pattern}

Figures 6 and 7, represents the simulated 3D gain radiation pattern and polar plot of dual band E-shaped antenna gain at operating frequencies $900 \mathrm{MHz}$ and $1800 \mathrm{MHz}$. Figure 6a; Figure 7a shows that, the radiation pattern were symmetrical about broad side direction

The antenna radiates possibly in all direction to cover the range. However, it radiates more in positive $\mathrm{Z}$ - direction, since reflected by the ground plane. The user head in $\mathrm{Z}$ direction acts as obstacle and absorbs certain amount of radiated power in $\mathrm{Z}$ direction thereby decreasing the efficient performance of E- antenna. Figures 6(b) and 7(b) show the altered radiation pattern due to human head interaction which absorbs certain amount of power radiated by phone, there by impacting mobile phone E-antenna performance [9].

\section{Influence of near field on antenna performance}

Specific Absorption Rate is the subject of strict regulation for health protection. This section focuses to describe the impact of human head model interaction with mobile phone handset [8].

\section{Specific absorption rate}

SAR is the rate at which the RF energies are absorbed by a given mass of material, as evidenced by a rise in material temperature. The SAR distribution on head model is

Table 2 SAR averaged over $1 \mathrm{~g}$ and $10 \mathrm{~g}$ tissue when exposed to handheld device

\begin{tabular}{|c|c|c|c|c|c|c|}
\hline \multirow[t]{3}{*}{ Model } & \multicolumn{6}{|c|}{ Placement of mobile handset device with respect to head model } \\
\hline & \multicolumn{2}{|c|}{ Placed near $(d=0 \mathrm{~mm})$} & \multicolumn{2}{|c|}{$d=5 \mathrm{~mm}$} & \multicolumn{2}{|c|}{$d=10 \mathrm{~mm}$} \\
\hline & $0.9 \mathrm{GHz}$ & $1.8 \mathrm{GHz}$ & $0.9 \mathrm{GHz}$ & $1.8 \mathrm{GHz}$ & $0.9 \mathrm{GHz}$ & $1.8 \mathrm{GHz}$ \\
\hline 1-g SAR (W/Kg) & 6.87 & 23.5 & 2.36 & 19.69 & 1.009 & 13.8 \\
\hline $10-g$ SAR $(W / K g)$ & 3.65 & 15.95 & 1.38 & 10.09 & 0.632 & 7.68 \\
\hline Max SAR $(W / K g)$ & 1.004 & 24.604 & 0.354 & 19.88 & 0.154 & 13.55 \\
\hline Average SAR (W/Kg) & 0.067 & 0.438 & 0.041 & 0.432 & 0.027 & 0.418 \\
\hline
\end{tabular}


calculated by assessing the E field coupled density $(\rho)$ of the brain tissue layers and its conductivity $(\sigma)$.

$$
\operatorname{SAR}=\left(\sigma|E|^{2}\right) /(\rho)
$$
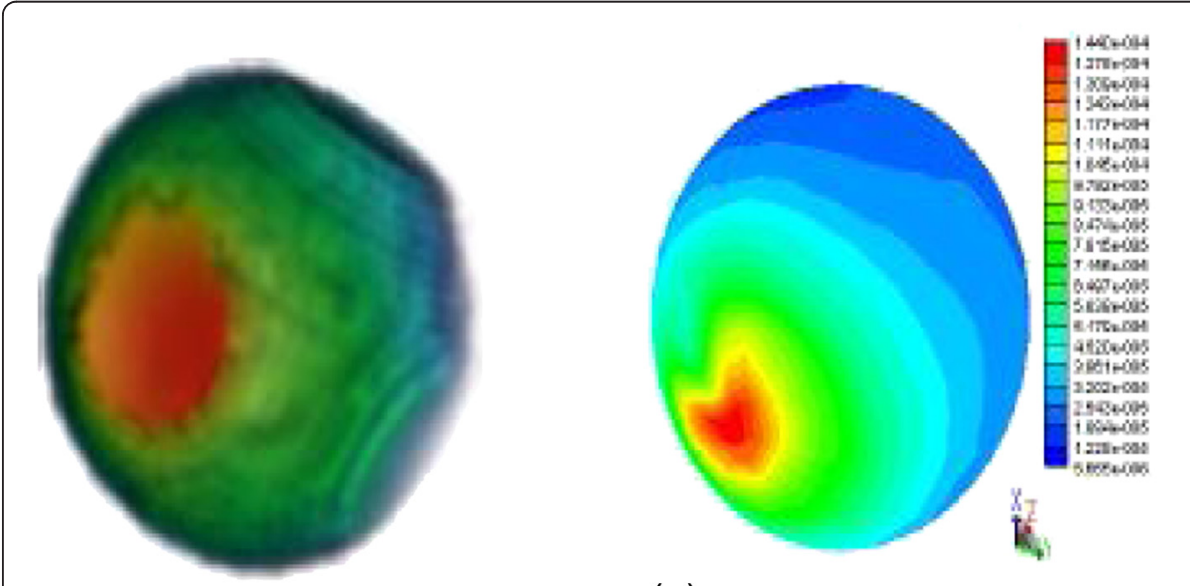

(a)
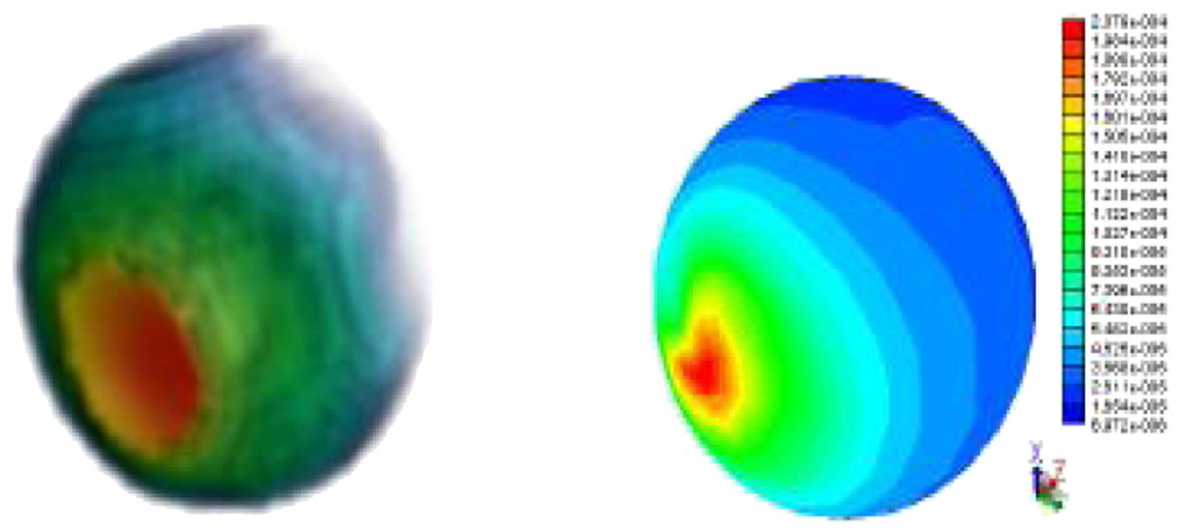

(b)
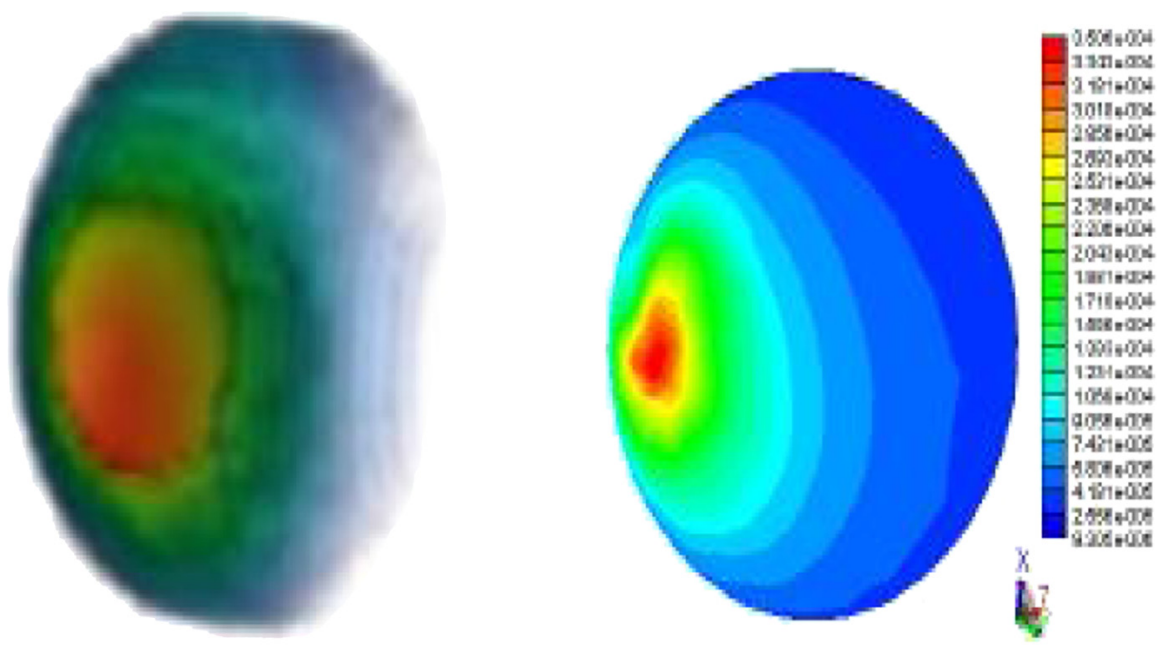

(c)

Figure $8 \mathrm{SAR}$, current distribution at $0.9 \mathrm{GHz}$. a) At $\mathrm{d}=0 \mathrm{~mm}$, b) at $\mathrm{d}=5 \mathrm{~mm}, \mathbf{c}) \mathrm{d}=10 \mathrm{~mm}$. 
SAR is averaged over tissue masses of 1 or $10 \mathrm{~g}$ tissue [5]. The human body which is a good conductor acts like a receiving antenna, absorbs the EM energy from the space. The tissues which are composed of different salts and organic compounds owns its
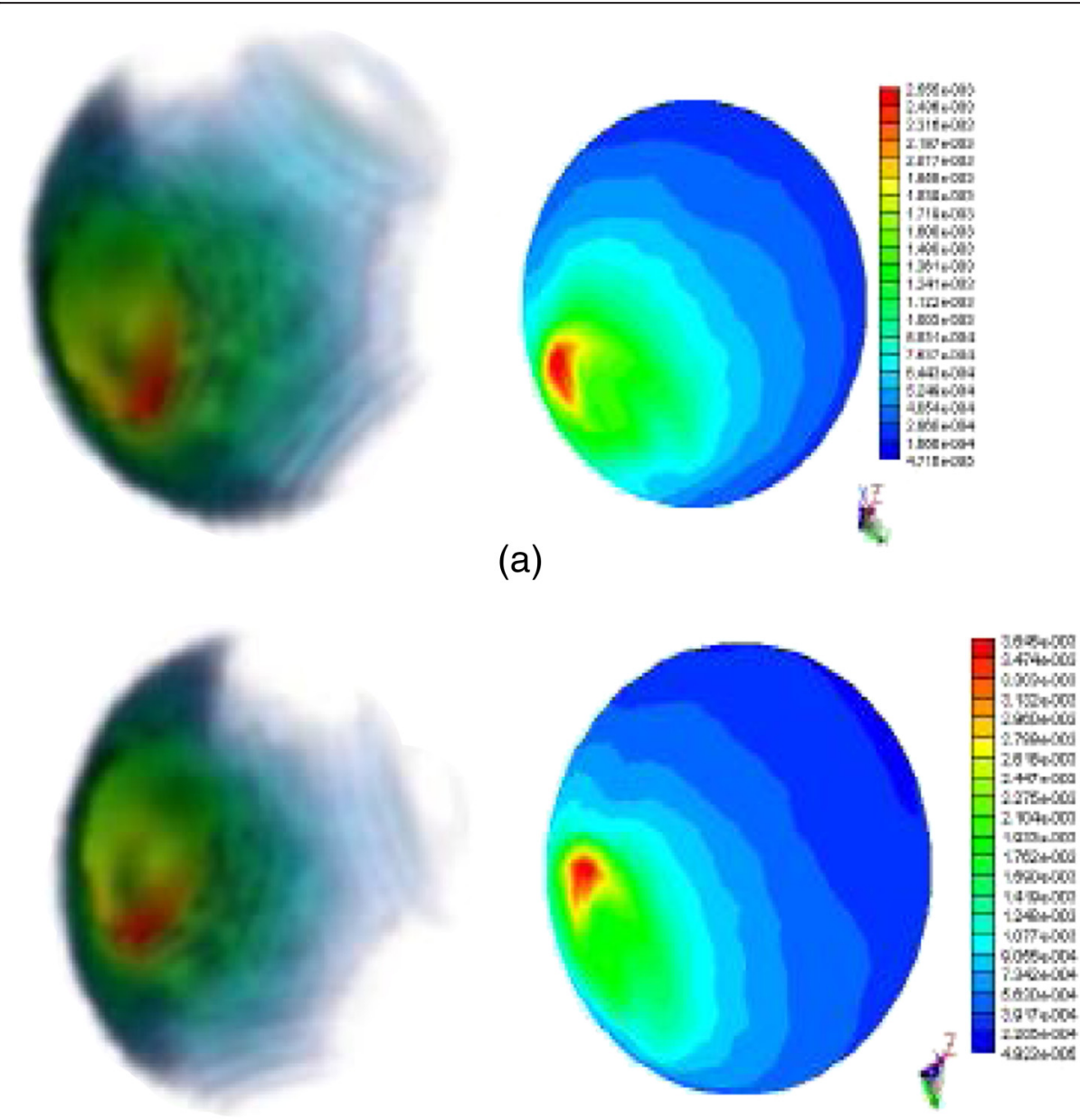

(b)
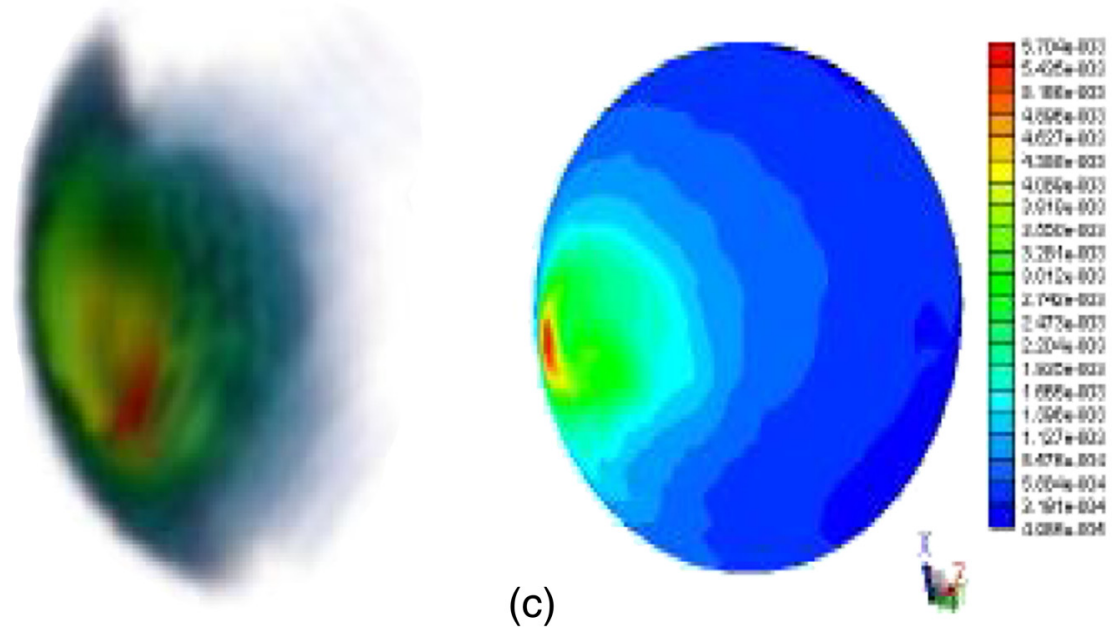

Figure 9 SAR, current distribution at $1.8 \mathrm{GHz}$. a) At $d=0 \mathrm{~mm}$, b) at $\mathrm{d}=5 \mathrm{~mm}, \mathbf{c}) \mathrm{d}=10 \mathrm{~mm}$. 
permittivity and conductivity which are also function of frequency, impacts the power coupled to tissues. The internal coupled fields can be calculated using numerical method based computational technique (FDTD), which gives information regarding realistic RF exposure.

\section{SAR analysis and discussions}

The SAR values were expressed in terms of Watts per Kilogram over $1 \mathrm{~g}$ and $10 \mathrm{~g}$ of the head tissues. Normally the distance between the head and the handset is around $10 \mathrm{~mm}$, during operation. Here, the power coupled to the head tissue is noted for three different distances i.e., $\mathrm{d}=0 \mathrm{~mm}$ (handset pressed to user head), $\mathrm{d}=5 \mathrm{~mm}$ and $\mathrm{d}=10 \mathrm{~mm}$. Table 2 give the SAR value for Spherical head model of user in free space for $900 \mathrm{MHz} / 1800 \mathrm{MHz}$.

The results indicate that, power coupled to the human tissue gets decayed with increase in distance from handset. SAR values are well below the SAR limit which substantiates the suitability of antenna design for wireless handheld device application, when handset is placed at $10 \mathrm{~mm}$ from the head, which is a normal placing position of phone during operation.

From the Figures 8 and 9, it is observed that more current is distributed in the side of the head and get fluctuates towards other side and is almost null current recorded on the other side of head. Similar case is observed in 3D- SAR distribution. The red colour (hot spot) in the figure indicates higher value of power coupled, where mobile handset is placed nearer. In general, the SAR in the head tissue decreases as the distance from the head to the handset increases.

\section{Thermal changes}

Thermal effects are mainly due to RF power absorbed by human tissues. Figures 10 and 11 show the 3D- thermal distributions in human brain tissue at $900 \mathrm{MHz} /$ $1800 \mathrm{MHz}$ operating frequency. Heat induced in the tissue might affect the proper functioning of cells or affect the cell metabolism [12]. However, the constant blood flow will maintain body temperature in equilibrium state. From the Figure 10 and Figure 11, it can be seen that, the brain side where a cell phone is used receives significantly higher dose of radiation when compared to other side. The variation in the thermal distribution in different human tissues is due to their conductivity and permittivity.

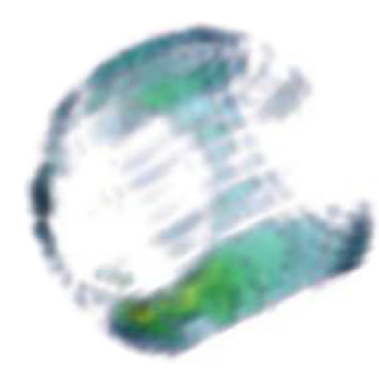

(a)

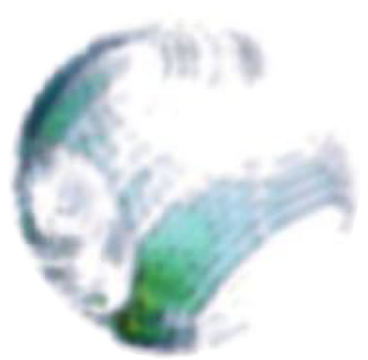

(b)

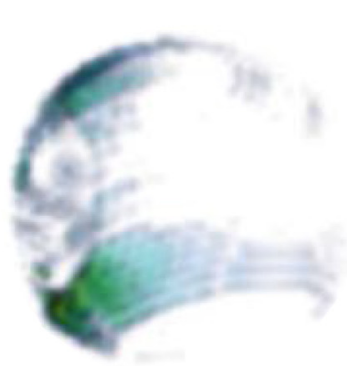

(c)

Figure 10 Thermal distribution at $0.9 \mathrm{GHz}$ [ a) at $\mathrm{d}=0 \mathrm{~mm}, \mathrm{~b})$ at $\mathrm{d}=5 \mathrm{~mm}, \mathrm{c}$ ) at $\mathrm{d}=10 \mathrm{~mm}$ ]. 


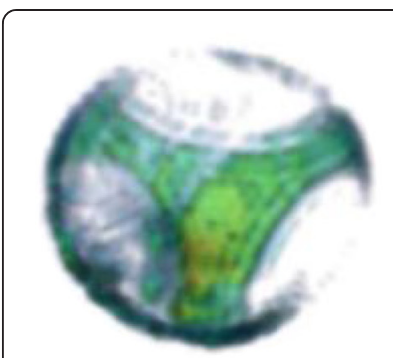

(a)

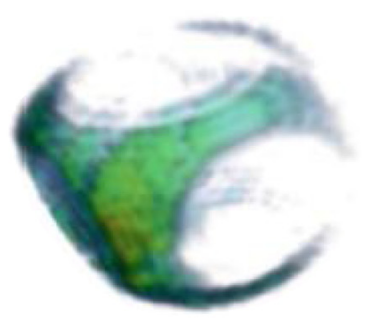

(b)

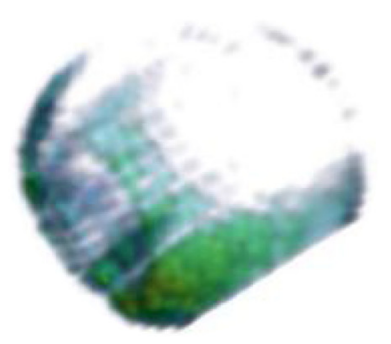

(c)

Figure 11 Thermal distributions at $1.8 \mathrm{GHz}$ [ a) at $\mathrm{d}=0 \mathrm{~mm}, \mathrm{~b})$ at $\mathrm{d}=5 \mathrm{~mm}, \mathrm{c}$ ) at $\mathrm{d}=10 \mathrm{~mm}$.

Figure 12a shows the graphical representations of variation in coupled power due to different distance of handset interaction for $0.9 \mathrm{GHz}$ frequency. It may be noted that, both the $1 \mathrm{~g}$ SAR and $10 \mathrm{~g}$ SAR are higher for the mobile phone antenna placed very nearer to head model and SAR value eventually decreases when the distance between antenna and head increases.

(a)

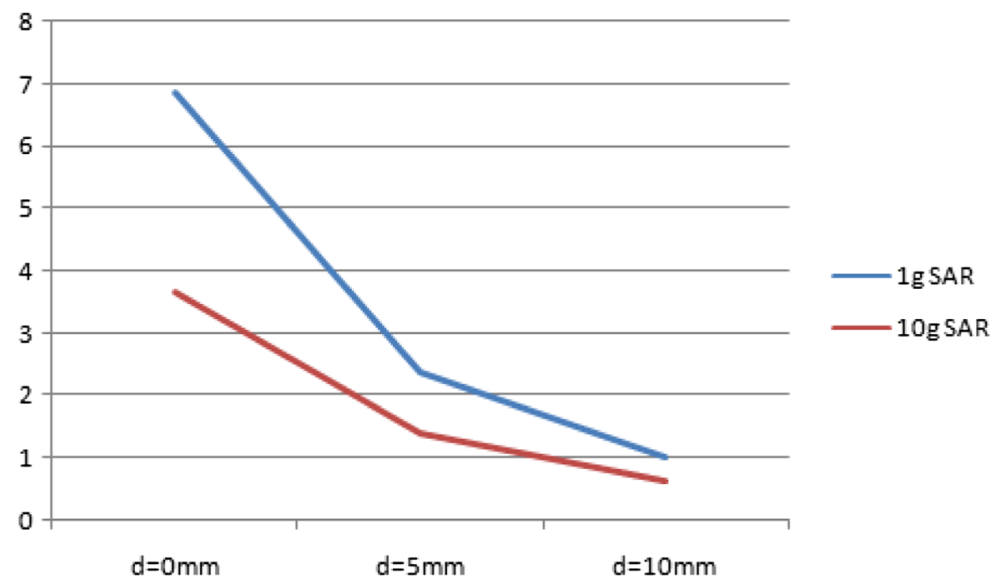

(b)

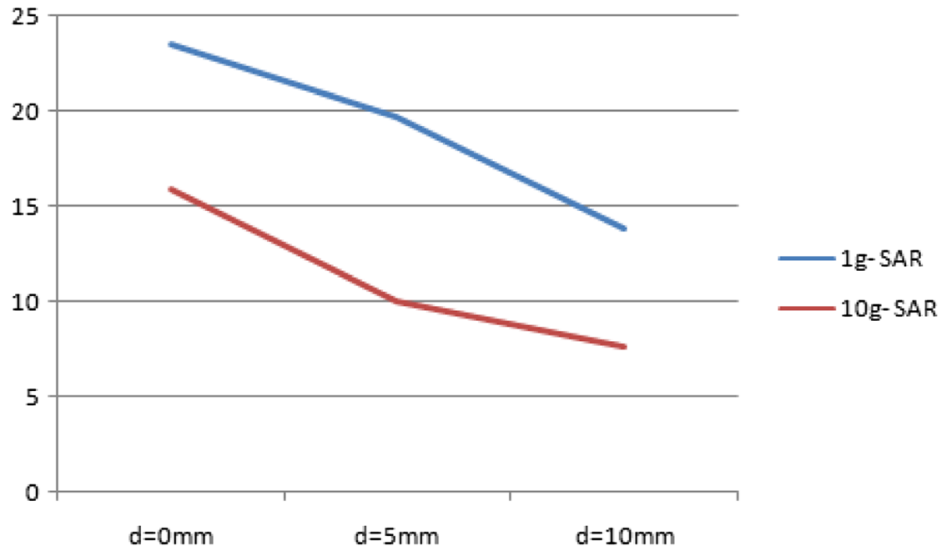

Figure 12 Graphical representation indicates higher SAR which is noted when interaction distance between mobile phone antenna and head decreases. a: Graphical representation of $1 \mathrm{~g}$ and $10 \mathrm{~g}$ SAR at $0.9 \mathrm{GHz}$. b: Graphical representation of $1 \mathrm{~g}$ and $10 \mathrm{~g}$ SAR at $1.8 \mathrm{GHz}$. 
From Figure 12b, it is observed that, for $1800 \mathrm{MHz}$ frequency, the $1 \mathrm{~g}$ SAR and 10d SAR are more than three times higher than SAR values observed at $900 \mathrm{MHz}$ operating frequency. The values used for comparison and analysis may be little bit inaccurate due to modeling of human head as layered spherical model which is far different from real time EM exposure to real human. However in this study, for both $0.9 \mathrm{GHz}$ and 1.8 $\mathrm{GHz}$ frequencies, $1 \mathrm{~g}$ and $10 \mathrm{~g}$ SAR values get decreased with increased separation between mobile and head model.

\section{Conclusion}

In this paper, a compact dual band $\mathrm{E}$ shaped antenna with comparatively low average SAR and better Bandwidth is introduced for GSM application in handheld devices. Simulations were performed for different scenarios. The antenna in free space and the handset device placed close to a user head model. The return loss was better than $25 \mathrm{~dB}$ at $900 \mathrm{MHz}$ and $1800 \mathrm{MHz}$ with bandwidth of $142 \mathrm{MHz}$ and $218 \mathrm{MHz}$ in the lower band and in the upper band respectively as compared to existing antennas. The $10 \mathrm{~dB}$ bandwidth of proposed E shaped antenna covers GSM 850/ GSM 900/ GSM 1800 bands. Further, the average specific absorption rate, due to human interaction with handset is well below the specified limit. The obtained results, including surface current distributions, S-parameters, radiation patterns, SAR values, have demonstrated that the proposed antenna design is suitable for GSM and 4G network and is able to achieve good performance for real world scenario.

Competing interests

The authors declare that they have no competing interest.

\section{Authors' contributions}

In this work, BR extended his constant guidance throughout the work, till final document verification. LR and BR together put forth the research idea and done simulation and documentation work. Both the author has read the final manuscript.

\section{Author's information}

Balamurugan Rajagopal: was born in Dindigul, Tamil Nadu, India on 1981. He is presently serving as an Assistant Director(Administration) in All India Council for Technical Education (AICTE), New Delhi on deputation from Department of Electrical and Electronics Engineering, Anna University, Regional Centre Coimbatore* where he has been serving as Assistant Professor (Power Electronics and Drives) since 2008(August) onwards. He completed B.Tech. degree in the specialization of Electronics and Instrumentation Engineering at Dr. B.R. Ambedkar National Institute of Technology(NIT), Jalandar (Punjab) in 2002 and M.E. degree (Power Electronics and Drives) at Government College of Technology, Coimbatore, Tamil Nadu in 2005. He joined Anna University, Chennai, India as Assistant Project Manager, Centre for Intellectual Property Rights and Trade Marks in February, 2006 and served until May, 2007. In June, 2007, he joined Anna University, Coimbatore as Project Manager, Centre for Intellectual Property Rights and in October, 2007, he was appointed as Assistant Professor (Faculty of Engineering and Technology, in which he continued prior to becoming to the present position of Assistant Professor (Power Electronics and Drives) in August, 2008. He also served as Asst. Controller of Examinations and Assistant Director (Centre for University Industry Collaboration) in Anna University of Technology, Coimbatore (Formerly Anna University, Coimbatore). He was granted two Erasmus Mundus Fellowships(Heritage \& India4EUII), funded by European Commission to undertake Staff Mobility Programme in Univ. of Seville, Spain and Aalto University, Finland respectively in 2013. He successfully completed Staff Mobility Programme in Univ. of Seville, Spain in Oct., 2013. He is a member of IEEE and various IEEE societies (ComSoc, CIS, CSS, EDS, EMCS, IES, I\&MS, MTT-S, PELS \& RAS). His fields of interests are Intellectual Property Rights, Electronics, Information \& Communication Technologies (E, I\&CT), Mobile Phone Radiation Issues, Electrical Drives, Embedded Control Systems, Power Electronics and VLSI Designs. Note: *-Formerly Anna University, Coimbatore in 2007 and renamed as Anna University of Technology, Coimbatore in 2010. Later merged with Anna University, Chennai on 1st August, 2012 by Government of Tamil Nadu. Lalithambika Rajasekaran: was born on 1987 in Erode, Tamil Nadu, India. She is Post Graduate Engineer. She was awarded B.E. and M.E. degrees by Anna University, Chennai. She completed M.E. (Electrical Drives and Embedded Control) by securing Gold Medal with 1st Rank during 2011-2013 in the Department of Electrical and Electronics Engineering, Anna University- Regional Centre Coimbatore, Tamil Nadu and B.E. (Electronics and Communication Engineering) during 2005-2009 in Anna University, Chennai. She is a member of IEEE and various IEEE societies (ComSoc, CSS, EDS, IES, SPS, MTT-S \& AP-S). Her fields of interests are Bio- Electromagnetics, Antennas for Wireless applications, Power Electronics for Renewable Energy Systems, Embedded Control Systems. 


\section{Acknowledgment}

Authors would like to thank Doctors of various hospitals for their valuable explanations concerning human tissue property.

Received: 25 May 2014 Accepted: 26 January 2015

Published online: 06 March 2015

\section{References}

1. Corbett R, Lam EY (2012) "Mobile-Phone Antenna Design", IEEE Antennas and Propagation Magazine, Vol. 54, No. 4

2. Yong J (2012) "Compact Dual-Band CPW-Fed Zeroth-Order Resonant Monopole Antennas "IEEE Antennas and Wireless Propagation letters, vol. 11

3. Fuguo Z, Steven G, Anthony TS H, Abd-Alhameed RA, See CH, Tim WC B, Jianzhou L, Gao W, Jiadong X (2014) Ultra-Wideband Dual-Polarized Patch Antenna With Four Capacitively Coupled Feeds. IEEE Trans Antennas Propag 62:5

4. Hassan Tariq C, Muhammad N, Abbasi QH, Yi H, AlJa'afreh SS (2013) "Compact Low-Profile Dual-Port Single Wideband Planar Inverted-F MIMO Antenna", IEEE Antennas and Wireless Propagation Letters, VOL. 12

5. Rowley JT, Rod BW (1999) Performance of Shorted Microstrip Patch Antennas for Mobile Communications Handsets At 1800 MHz'. IEEE Trans Antennas Propag 47:5

6. Jimmy T, Yih-Chien Chen C-YW (2012) "Dual- Band Planar Inverted F Antenna for Application in ISM, HIPERLAN, UNII and WiMAX", Proceedings of APMC

7. Luyi L, Jonathan R, Richard L (2013) Tunable Multiband Handset Antenna Operating at VHF and UHF Bands. IEEE Trans Antennas Propag 61:7

8. Md Faruk A, Sujoy M, Sudhabindu R (2009) "SAR Analysis in Human Head Model Exposed to Mobile Base-Station Antenna for GSM-900 band", Loughborough Antennas \& Propagation Conference

9. M. Ali, R. A. Sadler and G. J. Hayes (2002), "A Uni quely Packaged Internal Inverted-F Antenna for Bluetooth or Wireless LAN Application", IEEE antennas and wirele ss propagation letters, vol.1.

10. Qinjiang R, Kelce W (2011) Design, Modeling, And Evaluation Of A Multiband MIMO/Diversity Antenna System For Small Wireless Mobile Terminals'. IEEE Trans Components Packaging Manuf Technol 01:03

11. Simulation tool, 'General Electromagnetic Simulator', http://www.2comu.com

12. Sooman P, Juyoung J, Yeongseog L (2004) "Temperature Rise in the Human Head and Brain for Portable Handsets at 900 and $1800 \mathrm{MHz}^{\prime \prime} 4^{\prime}$ Intemational Conference on Microwave and Millimeter Wave Technology Proceedings

13. Mantash M, Collardey S (2013) Dual-band Wi-Fi and 4G LTE textile antenna". 7th European Conference on Antennas and Propagation (EuCAP) 8-12:422-425

14. Zuxing L, Minseok H, Jaehoon C (2012) Compact dual-band MIMO antenna for 4G USG dongle application". Microw Opt Technol Lett 54(3):744-748

15. http://en.wikipedia.org/wiki/List_of LTE networks // LTE network frequency range - world wide//.

16. M.E. de Cos, M.Mantash, "Dual-band coplanar waveguide feed smiling monopole antenna for Wi-FI and 4G LTE applications", IET Microwave, Antennas and Propagation, Vo. 7, Issue No. 9

17. Electromagnetic Simulation Software. Solutions for Design Engineers and EM Simulation Professionals, www remcom.com // comparison about FEM, FDTD and FEM-FDTD//.

18. Rozlan Alias, Simulation of radiation performance for mobile phones using a hybrid FEM-TFDTD computational technique. 4th Int. Conference on Modeling, Simulation and applied optimization (ICMSAO), 2011. doi:10.11.1109/ICMSAOL2011, pp. 577-5956

19. Erdem OFLI, Chung-Huan LI (2008) Analysis and optimization of mobile phone antenna radiation performance in the presence of head and hand phantoms". Turk J Elect Engg 16:1

20. Claudio R, Fernandez (2004) FDTD simulations and measurement for cell phone with planar antennas". Ann Telecommun 59(9-10):1012-2030

21. Md Mahabub A, Md Suaibur R (2013) A Connected E-Shape and U-Shape Dual-Band Patch Antenna for Different Wireless Applications". Int J Sci Eng Res 4:1

22. Wen Piao L, Dong-Hua Y, Zong-De L (2014) Compact Dual-Band Planar Inverted-e-Shaped Antenna Using Defected Ground Structure". Int J Antennas Propagation 937423:10 